\title{
Power Quality Events Classification on Real-Time Voltage Waveform Using Short Time Fourier Transform and Bayes Classifier
}

\author{
Okelola, Muniru Olajide \\ Department of Electronic \& Electrical Engineering \\ Ladoke Akintola University of Technology \\ Nigeria
}

\begin{abstract}
The increased use of non-linear loads and the occurrence of faults on the power systems have resulted in deterioration in the quality of power supplied to the end users. Power quality $(P Q)$ events and other disturbances lead to either malfunctioning or complete failure of electrical lelectronic equipment. Voltage dip, voltage swell, voltage interruption and harmonic distortions among others are the most common types of power quality $(P Q)$ events. Accurate and timely detection of these $P Q$ events is very essential for adequate corrective measures to be taken. This paper investigates such events by employing the use of Short Time Fourier Transform (STFT) for PQ events detection on a real-time voltage waveform, and Nä̈ve Bayes classifier for event classification. The Nä̈ve Bayes Classifier was trained using some generated synthesized parameters to model the common $P Q$ events. The results revealed that the technique classifies voltage $P Q$ events with high accuracy.
\end{abstract}

Keywords: power quality, voltage swell, voltage dip, harmonic distortions, short-time fourier transform, bayes classifier

\subsection{Introduction}

Power quality analysis was introduced at the end of the $19^{\text {th }}$ century; it was found that rotating machines and transformers were the major sources of the waveform disturbance [Okelola, 2015;Sumalatha\& Sankar, 2013].A power quality disturbance is generally defined as any change in power (voltage, current, and frequency) that interferes with the normal operation of electrical equipment [Halpin, \&Card, 2011; Mahela, Shaik, \&Gupta, 2015a; Ozgonenel, Yalcin, Guney, \& Kurt, 2013; Swamy, Kumar, \& Prasad, 2013]. The distribution of electrical energy requires high level of reliability for the proper functioning and longevity of industrial equipment and home appliances. Electrically operated Machines used in the industries are sensitive to fluctuation in the supplied voltage hence causing the multi-national companies to have their off grid generating plants as an alternative means of reducing the PQ problem.

The advent of smart grid had enabled the use of distributed generation systems which at the moment is grossly taking over the existing traditional grid system; consequently the use of electronic switching devices is on the increase thereby adding to the distortion existing on the power line. The use of nonlinear loads in industries nowadays is on the increase and it needs to be emphasized that these nonlinear loads is a threat to the power system. Also, usage of renewable energy sources with distribution system is a potential cause of variety of problems that must be detected and processed for corrective or preventive measures[Chang, \&Chan, 2015; Fakolujo, Adejumobi, \&Ogunyemi, 2012]

To prolong the service of life sensitive industrial equipment, protection against steady state distortion and temporary transients in the distribution lines should be promptly addressed [Fernandez-comesana, et al.,2012; Yu, et al., 2013]. Generally, power quality events in electrical power system could manifest inform of voltage sags, voltage variations, interruption, voltage swells, brownouts, blackouts, voltage imbalance, harmonics distortion, harmonic resonance, inter-harmonics, notching, noise, impulse, spikes (voltage), crest factor, electromagnetic compatibility, dropout, fault, flicker, transient, overvoltage, and under voltage[Khalid, \& Dwivedi, 2011] among others.For a particular analysis, features of interest could be extracted using Wavelet Transform (WT), Fourier Transform (FT), Hilbert Hung Transform (HHT) and S-Transform[Khalid, \& Dwivedi, 2011]. 
The next stage after feature extraction is classification which could be done using mathematical- based classifiers such as artificial neutral network (ANN), fuzzy logic (FL), support vector machine (SVM) and Bayesian classifier[Mahela, Shaik, and Gupta, 2015a; Yu, et al., 2013].

In this research, STFT was used for feature extraction and Naïve Bayes classifier was then employed for the classification of features detected. The revised version of Fourier transform is STFT; it is as well nomenclature as the sliding window version of the Fast Fourier Transform (FFT) which shows better results in terms of resolution and frequency sensitivity. In STFT, the signal is divided into small enough segments and these segments (portions) of the signal can be assumed to be stationary [Ingale, \&Tawade, 2013; Mahela, Shaik, \&Gupta, 2015a; Srividya, Muni Sankar, \& Devaraju, 2013]. Bayesian Network being a probabilistic framework finds application in reliability studies particularly in the area of power system reliability assessment.

Bayesian Networks (BNs) that combine probability and graph theory is still the most efficient models to represent uncertain information and inferences contained. The area of application of BNs in the field of engineering is inexhaustive, few among them include; finding of fault locations on a distribution feeder, prediction of weatherrelated failures of overhead distribution lines, diagnosis of fault in electric machines and electrical equipment, contingencies ranking resulting from terrorism, identification of causes of forced outage and power quality analysis [Ebrahimi, \& Daemi, 2010; Neelon, \& O’Malley, 2010].

The rest of this paper is organized as follows: Section 2, presents the research methodology. Section 3, presents the results and discussion while Section 4, presents the conclusion and future recommendation.

\subsection{Research Methodology}

This research work was carried out on the home-based electrical/electronic appliances with a view to analyze the type of PQ event(s) present. The appliances used in the study are blender, fan, washing machine, television (TV), vacuum cleaner, laptop and refrigerator. The experiment was conducted using real-time voltage signal waveforms at $220 \mathrm{~V}, 50 \mathrm{~Hz}$ supply. Power quality analyzer FLUKE 435(FLUKE 2006) was used to acquire voltage and frequency data. The FLUKE 435 was connected at the point of common coupling (PCC) to the above mentioned home-based electrical / electronic equipment. MATLAB (R2016b, Version 9.1) was used as implementation tool for processing the data acquired. Naïve Bayes classifier was sufficiently trained with synthetic voltage waveforms generated with selected PQ events of interest and STFT was used to analyze the fundamental voltage magnitudes being the triggering points on the signal waveform for the detection and segmentation of events. Signal energy and the total harmonic distortion (THD) from the $2^{\text {nd }}$ to $25^{\text {th }}$ order harmonics were the extracted features from selected PQ events.

\subsection{Mathematical Modeling Feature Extraction of PQ Events}

Parseval's theorem was used in the computation analysis of the STFT aimed at detecting the triggering points of a PQ event(s) in a voltage waveform. Fourier series function can be expressed as;

$f(x)=\frac{1}{2} a_{o}+\sum_{n=1}^{\infty} a_{n} \cos (n x)+\sum_{n=1}^{\infty} b_{n} \sin (n x)$

Bessel's inequality becomes

$\left[f(x)^{2}=\right.$

$\frac{1}{4} a_{o}^{2}+a_{o} \sum_{n=1}^{\infty}\left[a_{n} \cos (n x)+b_{n} \sin (n x)\right]+\sum_{n=1}^{\infty} \sum_{n=1}^{\infty}\left[a_{n} a_{m} \cos (n x) \cos (m x)+a_{n} b_{m} \cos (n x) \sin (m x)+\right.$

ambnsin $n x \cos m x+b n b m \sin n x \sin m x]$

By integrating equation (2) we have;

$\int_{-\pi}^{\pi}[f(x)]^{2}=$

$14 a 02-\pi \pi d x+a o-\pi \pi n=100 a n \cos n x+b n \sin n x d x$

$+-\pi \pi n=1 \infty n=1 \infty[$ anam $\cos n x \cos m x+a n b m \cos n x \sin n x a m b n \cos m x \sin n x+b n b m \sin m x \sin \sigma(n x) d x$

$$
\begin{aligned}
& =\frac{1}{4} a_{o}^{2}(2 \pi)+a_{o}(0)+\sum_{n=1}^{\infty} \sum_{n=1}^{\infty}\left[a_{m} a_{n} \pi \delta n m+0+0+b_{n} b_{m} \pi \delta m n\right] \\
& =\int_{-\pi}^{\pi}[f(x)]^{2} d x=\frac{1}{2 \pi} a_{o}^{2}+\sum_{n=1}^{\infty}\left(a_{n}^{2}+b_{n}^{2}\right)
\end{aligned}
$$

Complex Fourier series can be represented as;

$\frac{1}{2 \pi} \int_{-\pi}^{\pi}|f(x)|^{2} d x=\sum_{n=1}^{\infty}\left|a_{o}\right|^{2}$

2.2. A Flow Chart Showing the Procedural Steps for the Proposed Approach 
The process of detecting and classifying a PQ event from a voltage waveform is as showed in Figure 1 below.

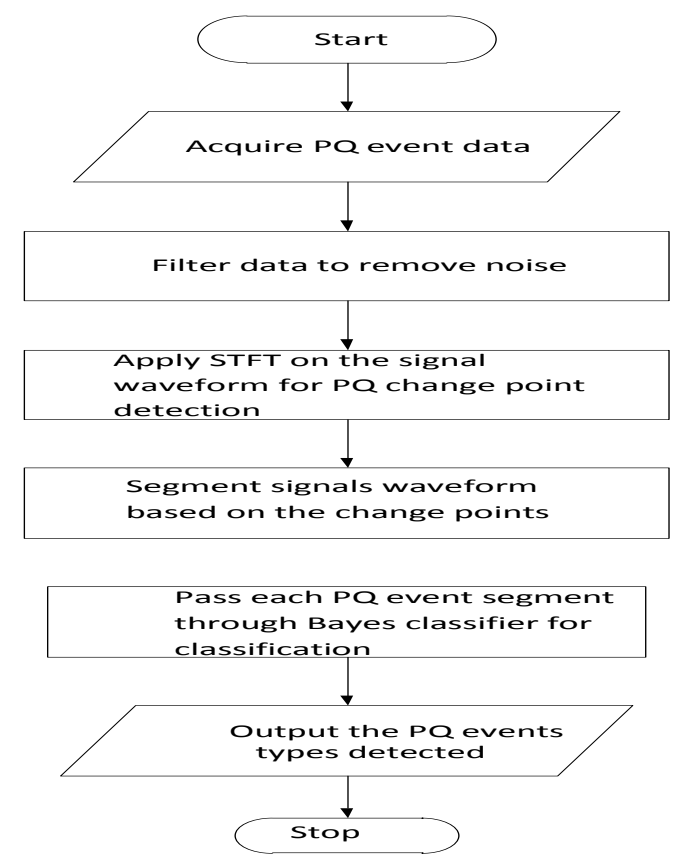

Figure 1: Flow chart for the PQ event classification and detection of real-time signal

\subsection{Results and Discussion}

STFT was used to analyze the acquired waveform for each of the appliances for the detection of voltage sag, swell or interruption.

\section{Case A: Detection and Classification of PQ Event in Laptop}

Figure 2 presents the voltage and frequency waveform of laptop, the observed PQ event that occurred in the laptop was the voltage dip, and this was evidently visible in the voltage signal waveform. The event occurred between $200-250$ time samples, and the time of occurrence was found to be within the range of $8 \times 10^{4}$ to $14 \times 10^{4}$ seconds. Also, harmonic contents were observed before, during and after the voltage dip.
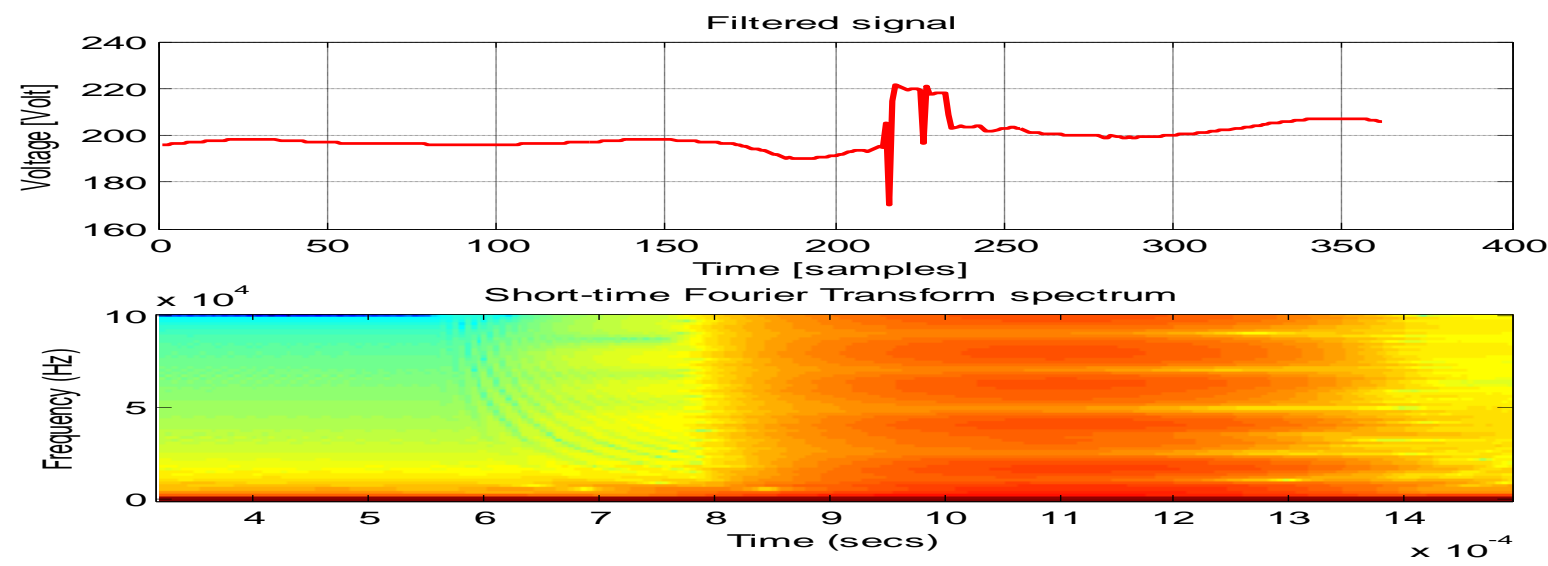

Figure2: Voltage and Frequency Waveform for the Laptop

\section{Case B: Detection and Classification of PQ Event in Washing Machine}

Figure 3 illustrated the voltage and frequency waveform of washing machine, the PQ event present was voltage dip. From the wave form, the event occurred at six different points on the waveform and they are between 5001000, 1400- 1700, 2000, 2800-3400, 3800- 4000, 4700- 4800 sampled times. The time of occurrence of the detected PQ event is as well shown on the waveform; it is glaring that voltage dip being the detected PQ event 
appears more on the voltage frequency waveform of washing machine compared to that of laptop shown in Figure 2 above.
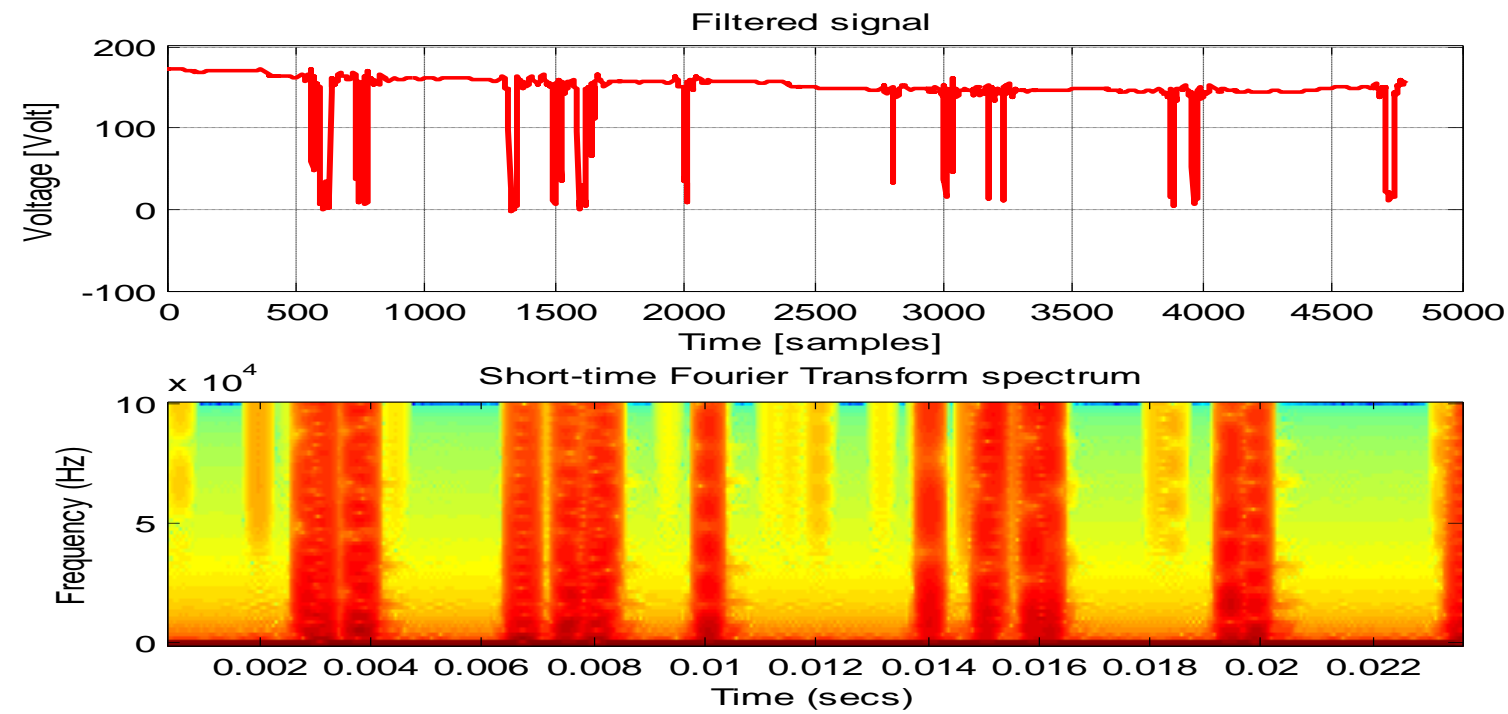

Figure 3: Voltage and Frequency Waveform for the Washing Machine

\section{Case C: Detection and Classification of PQ Event in Fan}

Figure 4 illustrated the voltage and frequency waveform of standing fan, the PQ event present was voltage dip, the waveform shows undulating shape and at 210 sampled times, there was steeped decrease in the waveform shape.
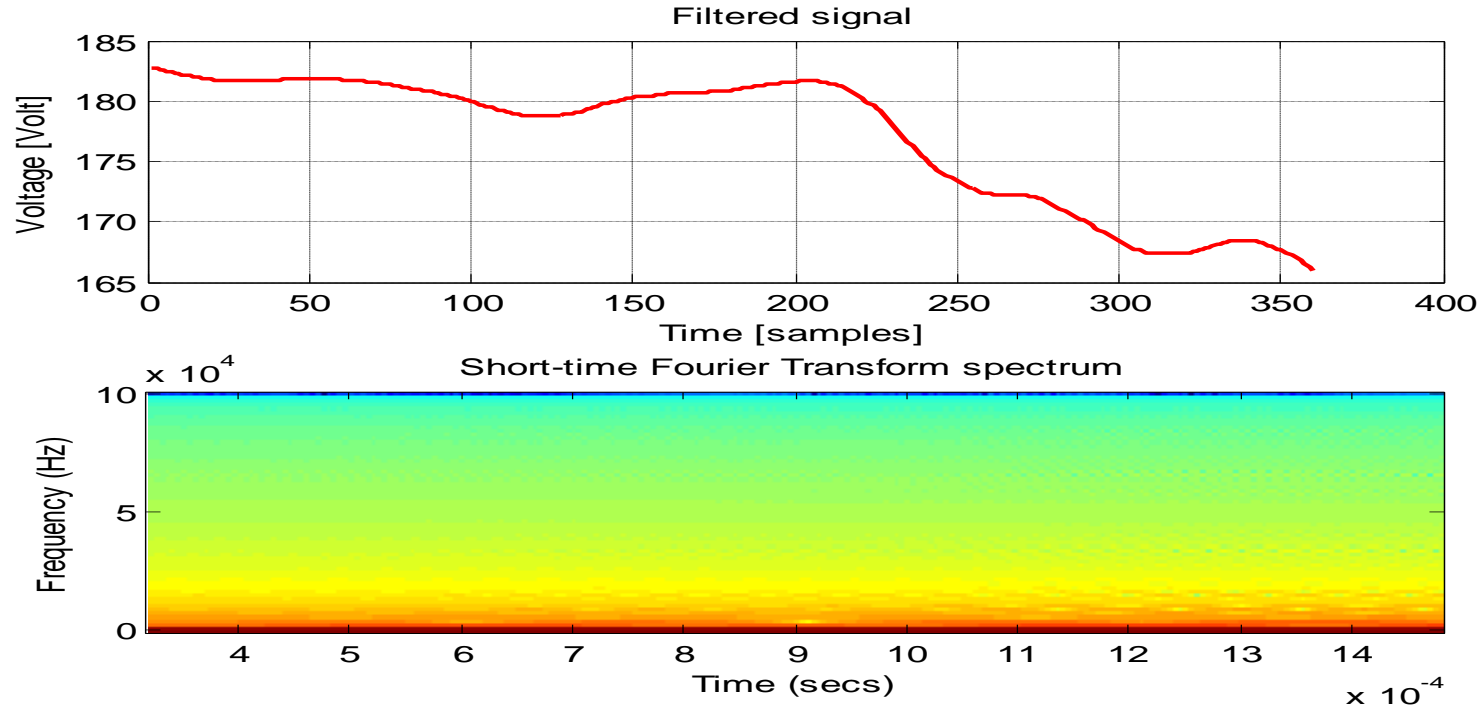

Figure 4: Voltage and Frequency Waveform for the Standing Fan

\section{Case D: Detection and Classification of PQ Event in Vacuum Cleaner}

Figure 5 illustrated the voltage and frequency waveform of Vacuum Cleaner, the PQ events present were voltage swell and brownout, the waveform maintained a steady shape with slight undulating shape between 0 to 1000 sample times, with a swell in shape between 1450 to 1950 sampled times and a sharp decreased (brownout) in voltage level to almost 10Volt between 1950 - 2000 sampled time. 

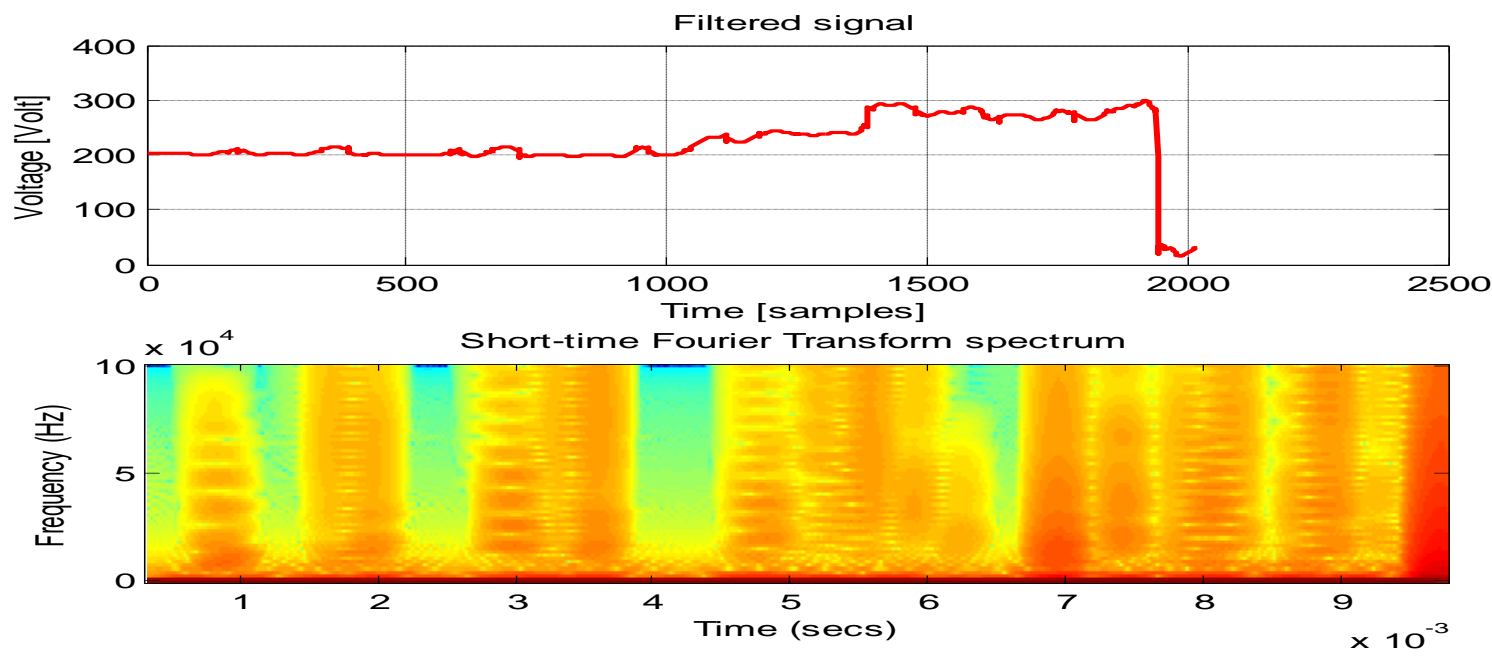

Figure5: Voltage and Frequency Waveform for the Vacuum Cleaner

\section{Case E: Detection and Classification of PQ Event in Television (TV)}

The observed PQ event in the voltage and frequency waveform for TV was also voltage dip represented by Figure 6. It was conspicuously seen between 0 to 50 and 50 to 150 sampled times. The waveform maintains a relatively steady shape till about 370 sampled times.
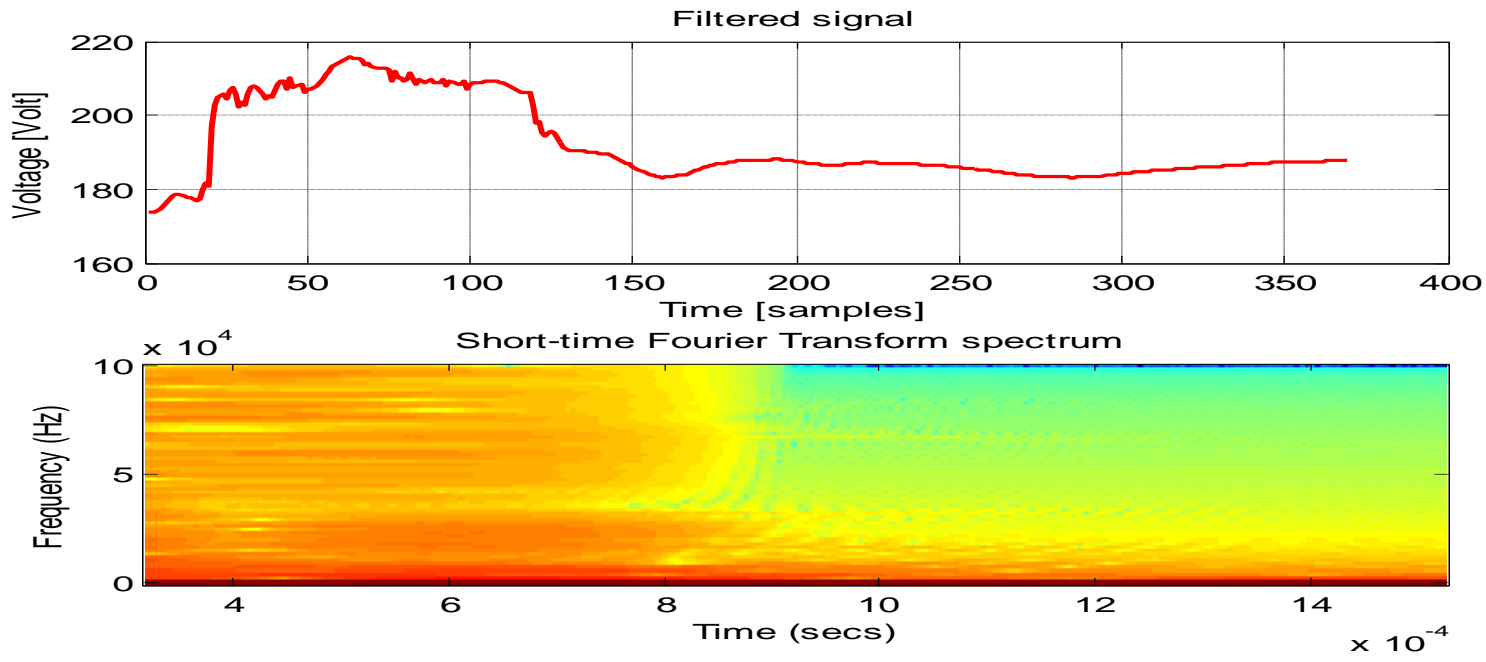

Figure 6: Voltage and Frequency Waveform for the TV

\subsection{Conclusion}

The performance of STFT for PQ events detection as well as the use of Naïve Bayes for events classification was presented in this paper. The study was carried out on real-time voltage signals supplied to some home-based electrical/electronic appliances. The results showed that the STFT-Bayes technique gives a good accuracy in the detection and classification of PQ (voltage) events detected. The main drawback associated with the proposed technique was occasional inability to distinguish clearly between dip and normal segments in the signal waveform as indicated in the washing machine and vacuum cleaner. Further research work can consider the use of 3-phase electrical devices, in order to investigate the efficiency of the proposed approach on 3-phase system.

\section{References}

Okelola, M.O. (2015). Detection and classification of power quality event using discrete wavelet transform and support vector machine. International Journal of Engineering Research \& Technology, 4(6), 338-342.

Sumalatha, A., and Sankar, K. R. (2013). Power quality improvement of grid interconnected 3- phase 4-wire system of distribution generation. International Journal of Scientific and Research Publications, 3(6), 1-8. 
Halpin, S. M., and Card, A. (2011). Power quality. In d. Muhammad h. Rashid, ph (ed.), Power Electronics Handbook Devices, Circuits, and Applications (Thrid Edit, p. 1409). Butther-Heinenemann.

Mahela, O. P., Shaik, A. G., and Gupta, N. (2015a). A critical review of detection and classi fi cation of power quality events. Renewable and Sustainable Energy Reviews, 41, 495-505.

Ozgonenel, O., Yalcin, T., Guney, I., and Kurt, U. (2013). A new classification for power quality events in distribution systems. Electric Power Systems Research, 95, 192-199.

Swamy, B. K., Kumar, P. P., and Prasad, C. V. (2013). A MATLAB based power quality analyzer (PQA) for enhancing power quality in the system. International Journal of Electrical and Electronics Engineering Research, 3(1), 73-86.

Chang, Y., and Chan, Y. (2015). The minimization of voltage sag effect for specially connected transformers with a sensitive load and distributed generation systems. Electrical Power and Energy Systems, 73, 882-890.

Fakolujo, A., Adejumobi, I., and Ogunyemi, J. (2012). Power quality assessment in nigerian distribution network. In EIE's@nd Intl' Conf.Comp., Energy, Net., Robotics and Telecom.| eieCon2012,pp. 103-111

Fernandez-comesana, P., Freijedo, F. D., Doval-gandoy, J., Lopez, O., Yepes, A. G., and Malvar, J. (2012). Mitigation of voltage sags, imbalances and harmonics in sensitive industrial loads by means of a series power line conditioner. Electric Power Systems Research, 84(1), 20-30.

Yu, N., Li, C., Li, R., Liu, W., and Yin, S. (2013). Classification of composite power quality disturbance signals based on HHT and, (Eeic), 416-421.

Khalid, S., and Dwivedi, B. (2011). Power quality issues, problems, standards and their effects in industry with corrective means. International Journal of Advances in Engineering and Technology (IJAET), 1(2), 1-11.

Ingale, R., and Tawade, L. (2013). Detection and comparison of power quality disturbances using different techniques. International Journal of Computer Applications, 75(18), 48-53.

Srividya, T., Muni Sankar, A., \& Devaraju, T. (2013). identifying, classifying of power quality $\backslash$ disturbances using Short Time Fourier Transform and S-Transform. Weekly Science Journal, 1(1), 1-6.

Ebrahimi, A., and Daemi, T. (2010). A simple approach to construct the Bayesian Network associated with electric transmission systems. International Review of Electrical Engineering, 5(1), 180-184.

Neelon, B., \& O'Malley, A. J. (2010). Bayesian analysis using power priors with application to pediatric quality of care.Journal of Biometrics \& Biostatistics, 1(1), 1-9.

APPENDIX A

Table A1:Standard Parameters for operating the FLUKE 435 PQ Analyzer

\begin{tabular}{cc}
\hline Electrical Parameter & Value \\
\hline Maximum Phase Voltage & $220 \mathrm{~V}$ \\
Minimum Phase Voltage & $180 \mathrm{~V}$ \\
Maximum Neutral Voltage & $3 \mathrm{~V}$ \\
Maximum Impulse Voltage & $500 \mathrm{~V}$ \\
Maximum Waveshape Voltage & $10 \mathrm{~V}$ \\
Maximum Frequency Deviation & $0.02 \mathrm{~Hz}$ \\
Minimum Power Factor. & 0.85 \\
Maximum Voltage T.H.D. & $5 \%$ \\
Maximum Current T.H.D & $20 \%$ \\
Maximum Voltage Imbalance & $2 \%$ \\
Maximum Current Imbalance & $5 \%$ \\
\hline
\end{tabular}

Table A2: Specifications of the Home-Based Electrical / Electronic Appliances

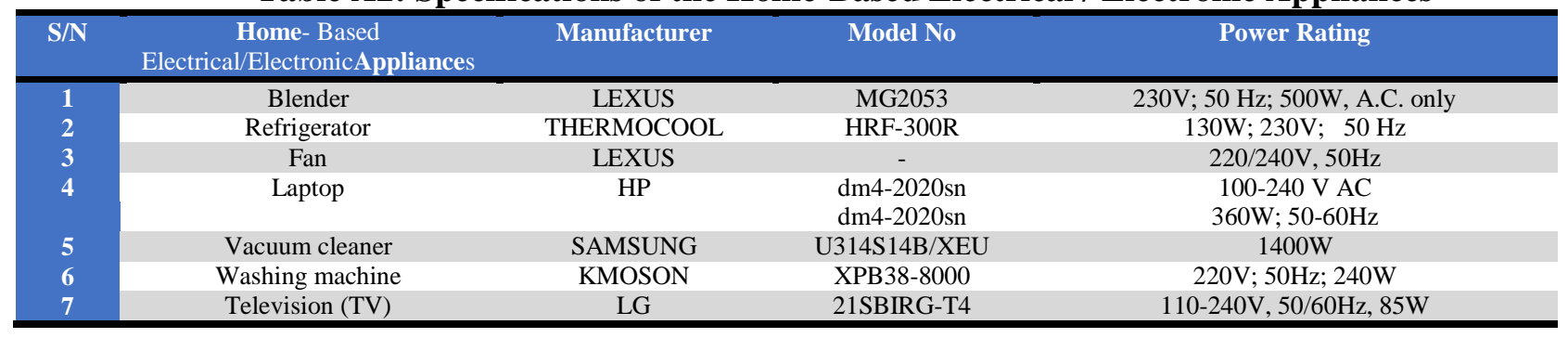


APPENDIX B: The use of FLUKE 435 for Measurement of Power Quality of Home-Based Electrical / Electronic Appliances

Plate B1: Acquisition and Analysis of Supplied Power Signal for Laptop by FLUKE 435

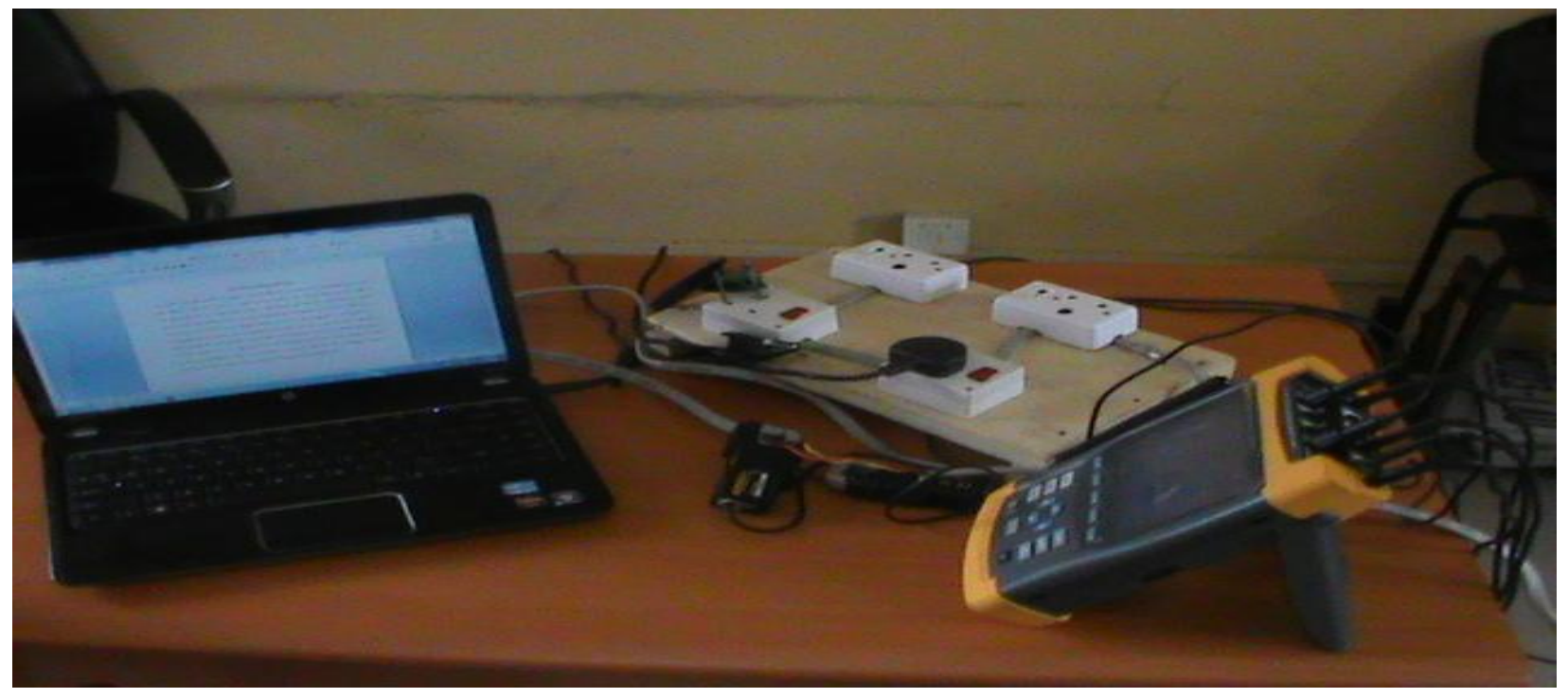

Plate B2: Acquisition and Analysis of Supplied Power Signal for Refrigerator by FLUKE 435

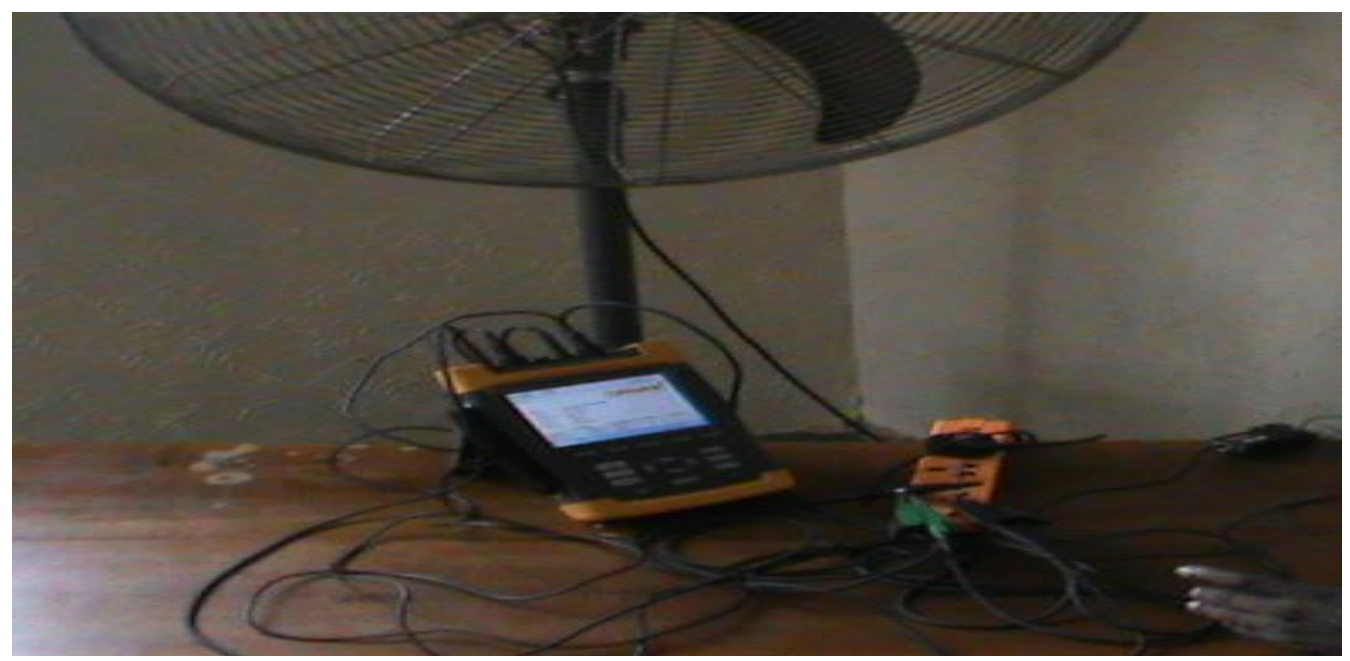

Plate B3: Acquisition and Analysis of Supplied Power Signal for Fan by FLUKE 435 


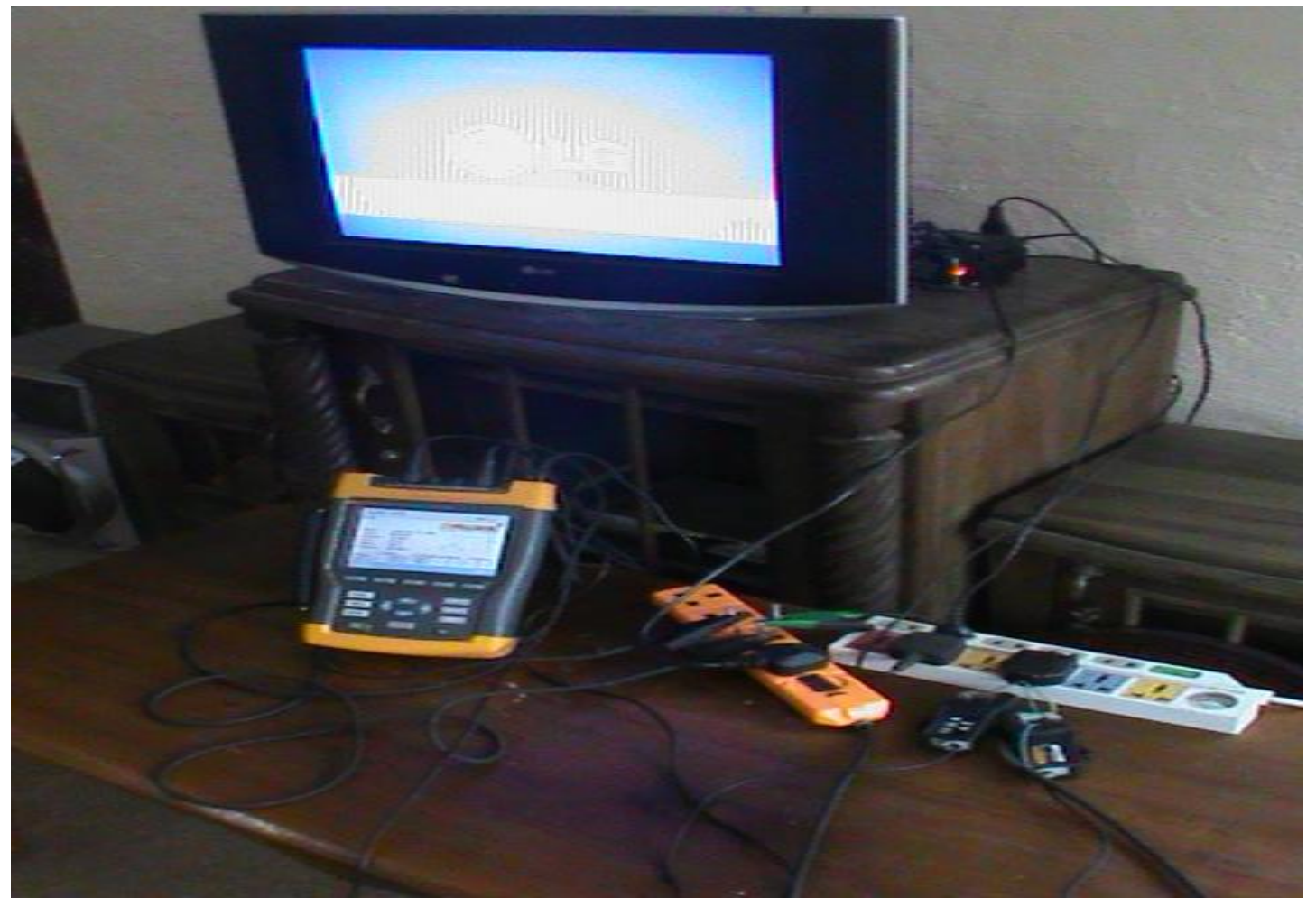

Plate B4: Acquisition and Analysis of Power Supplied Signal for TV by FLUKE 435. 


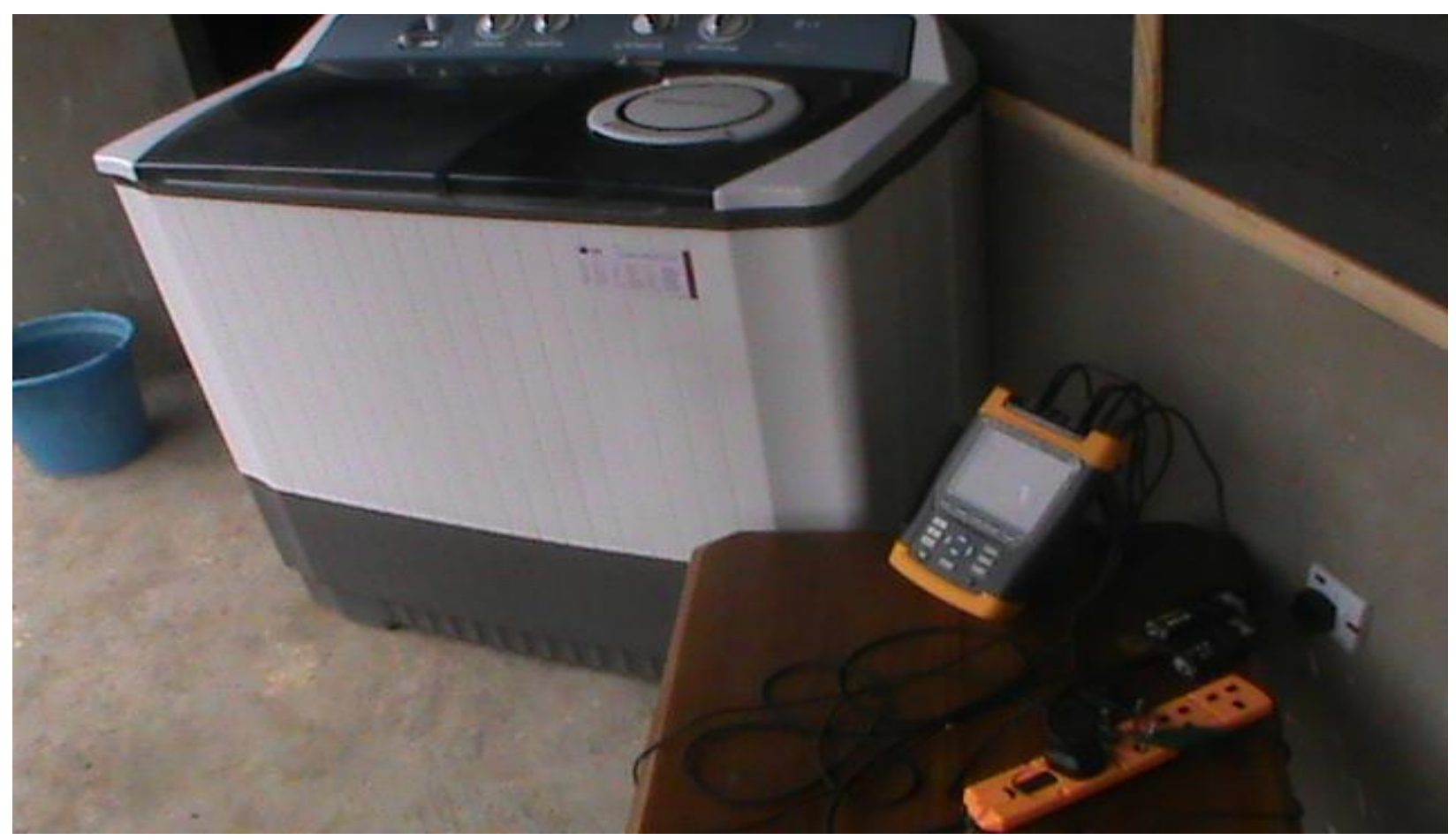

Plate B5: Acquisition and Analysis of Supplied Power Signal for Washing Machine by FLUKE 435

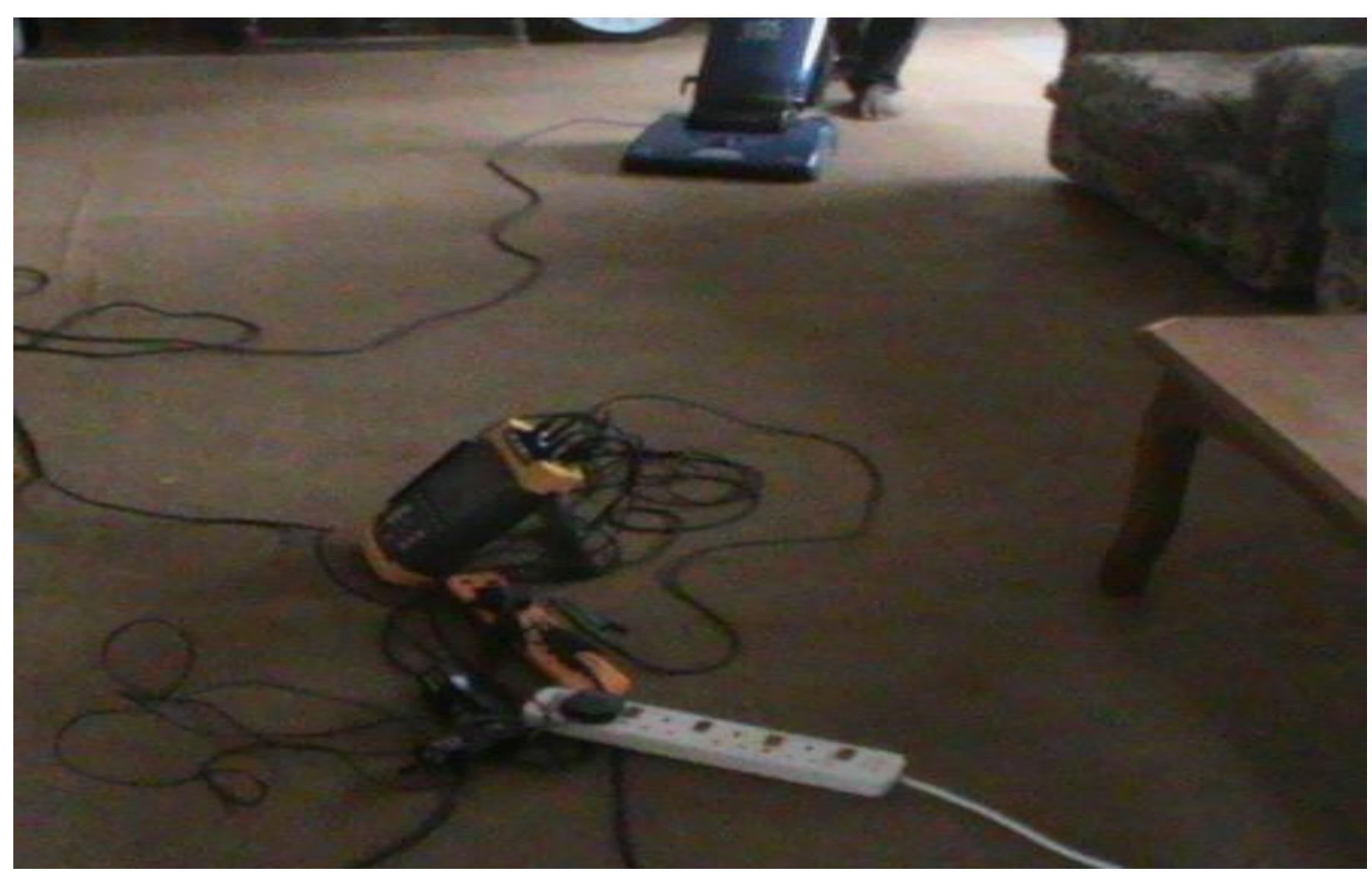

Plate B6:Acquisition and Analysis of Supplied Power Signal for Vacuum Cleaner by FLUKE 435 